\title{
Therapeutic Uses of Lycium barbarum Polysaccharides on Idiopathic Thrombocytopenic Purpura Mice via Inhibition of Oxidative Stress
}

\author{
Chengqiang Jin'1, Haixin Dong1, Jianwei Zhou ${ }^{1}$, Shuhua Lu1, Xiaxia Yang1, \\ Zhenwen Qian', Yanxia Jia ${ }^{2 *}$ \\ ${ }^{1}$ Analytical Section of Attached Hospital of Jining Medical College, Jining, China \\ ${ }^{2}$ Radiology Department of Jining No. 1 People's Hospital, Jining, China

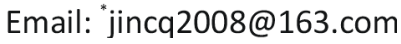

Received 28 June 2016; accepted 5 August 2016; published 8 August 2016

Copyright (C) 2016 by authors and Scientific Research Publishing Inc.

This work is licensed under the Creative Commons Attribution International License (CC BY). http://creativecommons.org/licenses/by/4.0/

(c) (i) Open Access

\section{Abstract}

The aim of the present study was to investigate the effect of Lycium barbarum polysaccharides (LBP) on the treatment of ITP mice and to explore its mechanism. Forty idiopathic thrombocytopenic purpura (ITP) mice were divided randomly into a model control group and LBP groups I, II, III and IV. ITP mice in LBP groups I, II, III, and IV were administered LBP at four different doses (50, 100, 200 and $400 \mathrm{mg} \cdot \mathrm{kg}^{-1} \cdot \mathrm{d}^{-1}$, respectively) for 7 days by gavage. Blood samples were collected from the tail veins of the mice after treatment. Platelet counts were determined, and the total antioxidant status (TAS), total oxidant status (TOS) were measured with ELISA kits. The platelet count was (30.28 \pm 13.42) $\times 10^{9} / \mathrm{L}$ in the model control group, and the number of platelets in all LBP groups was higher than that in the model control group. The platelet count increased, and it reached $(67.09 \pm 10.81) \times$ $10 \%$ L in LBP group I; the platelet counts in the other three groups increased significantly compared to LBP group I, and they did not differ significantly. TAS concentrations in the LBP groups were significantly increased compared to the model control group, whereas TOS concentrations were significantly decreased. Taken together, these results indicate that LBP is effective at increasing the number of platelet (PLT), and LBP may treat ITP mice via suppressing oxidative stress.

\section{Keywords}

Lycium barbarum Polysaccharides, Idiopathic Thrombocytopenic Purpura, Total Antioxidant Status, Total Oxidant Status

\footnotetext{
${ }^{*}$ Corresponding author.
} 


\section{Introduction}

Idiopathic thrombocytopenic purpura (ITP) is defined as an isolated low platelet count with normal bone marrow and the absence of other causes of thrombocytopenia [1]. Lycium barbarum is wildly used both as a kind of medicinal herb and as a kind of food additive in many Asian countries, and Lycium barbarum polysaccharides (LBP), as a major cell component, has been reported to have many beneficial effects including anti-aging, neuroprotection, immune modulation, and anticancer properties. LBP has great potential use as a food supplement in the prevention of hepatic diseases because LBP is effective at reducing necroinflammation and oxidative stress induced by chemical toxins [2]. At present, there is no literature report on the treatment of idiopathic thrombocytopenic purpura with LBP in the world. We reported earlier that oxidants increase and antioxidants decrease in patients with chronic ITP [3]. Therefore, we infer that Lycium barbarum polysaccharides can ameliorate oxidative stress in ITP. The purpose of this study was to investigate whether LBP administration could treat ITP and its possible mechanism effectively in ITP mice.

\section{Materials and Methods}

\subsection{Materials}

Forty male and female BALB/c mice aged 3 months and weighing $19 \pm 3$ g were used throughout the experiments. These mice were purchased from the Animal Center of Guangdong Medical College. LBP (Specification: 100 g; molecular weight: 1,112,100 D; lot number: 985626; Shanxi Ruikang Bioengineering Co., Ltd., China). Alzet micro-osmotic pump (model 1002; Alza, Palo Alto, CA). Sysmex automatic hemocyte analyzer (XS800i; Sysmex Shanghai Ltd.). Anti mouse platelet membrane glycoprotein (GPIIb/IIIa) monoclonal antibody (Specification: $0.5 \mathrm{mg}$, BD Pharmingen, USA). Enzyme-linked immunosorbent assay kit for TAS (Specification: 1 Kit, Sigma-Aldrich Co. USA). Enzyme-linked immunosorbent assay kit for TOS (Specification: 1 Kit, Sigma-Aldrich Co. USA).

\subsection{Methods}

\subsubsection{ITP Mice Model}

This experiment was approved by amimal ethics committee of Affiliated Hospital of Jining Medical College and it was conducted from August to November 2015 in Animal Center of Guangdong Medical College. Mice were maintained under a 12-hour light-dark cycle at a temperature of $20^{\circ} \mathrm{C} \pm 2{ }^{\circ} \mathrm{C}$ and a humidity of $55 \% \pm 5 \%$; they were fed a standard diet and given access to water (4 to $7 \mathrm{ml}$ per day). A clinically more relevant model for testing LBP was obtained as follows, Anti mouse platelet membrane glycoprotein (GPIIb/IIIa) monoclonal antibody (MWReg 30) was continuously infused using an osmotic pump which was implanted into the subcutaneous tissue of mice with a pumping rate of $0.25 \mathrm{ml} / \mathrm{h}$ for 2 weeks. Blood samples were gotten under anesthesia at $0,4,5$, and 6 days to determine the platelet count [4] [5]; Sysmex XS800i automatic hemocyte analyzer was used. A chemical called EDTA was added to freshly-collected blood specimens to prevent clotting before the test began, and it was used to detect platelet counts.

\subsubsection{Treatment of ITP Mice with LBP}

After the ITP mice model was successfully established, the mice were divided into 5 groups randomly using the random number table method after the model was built, which included a model control group, LBP group I, LBP group II, LBP group III and LBP group IV. There were 8 mice per group, and all of them were included in the results analysis. LBP was dissolved in different concentrations using distilled water according to the weight of mice. Mice in LBP group I, LBP group II, LBP group III and LBP group IV were administered LBP at a dose of 50, 100, 200 and $400 \mathrm{mg} \cdot \mathrm{kg}^{-1} \cdot \mathrm{d}^{-1}$ per mouse, respectively, by gavage daily for 7 days, then blood samples were taken under anesthesia from the tail veins of the mice and PLT, TAS and TOS were determined. PLT was determined as follows: Click the "manual" button of XS800i Sysmex automatic hemocyte analyzer, select the "CBC" analysis mode and the sample pre dilution "yes" mode, click OK, then mix the sample well, press the "start" button to start analyzing the sample.

\subsection{Measurement of TAS and TOS}

In vitro enzyme-linked immunosorbent assay kits (Sigma-Aldrich) for quantitatively detecting mouse TAS and 
TOS in serum were used to detect the concentration of TAS and TOS respectively.

\subsection{Statistical Analysis}

All the experimental data were analyzed by SPSS 20.0 software (International Business Machines Corporation, Al Monk, New York, USA). The platelet counts and the concentrations of TAS and TOS in each experimental group and control group were expressed as the means $\pm \mathrm{SD}$, and measurement data differences between groups were compared by a t-test. Correlations between platelet count and TOS and TAS were conducted by a linear correlation.

\section{Results}

\subsection{Platelet Counts in Peripheral Blood of Mice in Each Group}

The platelet count was $30.28 \pm 13.42 \times 10^{9} / \mathrm{L}$ in the model control group, and the numbers of platelets in the LBP groups after treatment for 7 days were all higher than that in the model control group (see Figure 1, all $P<$ 0.05). Platelet numbers increased, reaching $(67.09 \pm 10.81) \times 10^{9} / \mathrm{L}$ in LBP group I; platelet counts in the remaining groups (LBP groups II, III, and IV) increased significantly compared to LBP group I ( $\mathrm{t}_{\text {IIII }}=9.53$, $\mathrm{t}_{\text {III-I }}=$ 6.57, $\mathrm{t}_{\mathrm{IV}-\mathrm{I}}=4.08$, all $P<0.05$ ), but they were not significantly different from each other (all $P>0.05$ ), and the platelet counts reached a steady state of approximately 3 times the control at a dose of $100 \mathrm{mg} \cdot \mathrm{kg}^{-1} \cdot \mathrm{d}^{-1}$. These results suggested an important role for LBP in curing ITP mice.

\subsection{Serum Total Antioxidant Status (TAS) and Total Oxidant Status (TOS) Concentration in Each Group}

TAS concentrations in the peripheral blood of mice administered with LBP for 7 days by gavage were significantly increased compared to the model control group $\left(\mathrm{t}_{\mathrm{I}-\mathrm{c}}=14.24, \mathrm{t}_{\mathrm{II}-\mathrm{c}}=19.53, \mathrm{t}_{\mathrm{III}-\mathrm{c}}=21.04, \mathrm{t}_{\mathrm{IV}-\mathrm{c}}=22.68\right.$, all $P<$ 0.05) (Figure 2), whereas TOS concentrations in the peripheral blood of mice administered with LBP significantly decreased $\left(\mathrm{t}_{\mathrm{I}-\mathrm{c}}=10.24, \mathrm{t}_{\mathrm{II}-\mathrm{c}}=12.06, \mathrm{t}_{\mathrm{III}-\mathrm{c}}=12.14, \mathrm{t}_{\mathrm{IV}-\mathrm{c}}=12.35\right.$, all $\left.P<0.05\right)$ (Figure 3$)$.

\subsection{Correlation Analysis of Platelet Count, TAS and TOS}

The correlation between platelet count and TAS was assessed in all groups. There is significant positive correlation between the platelet count and TAS ( $r=0.989, P=0.0005)$ (Figure 4). Moreover, significant negative correlation existed between the platelet count and TOS $(r=-0.952, P=0.0009)$ (Figure 5).

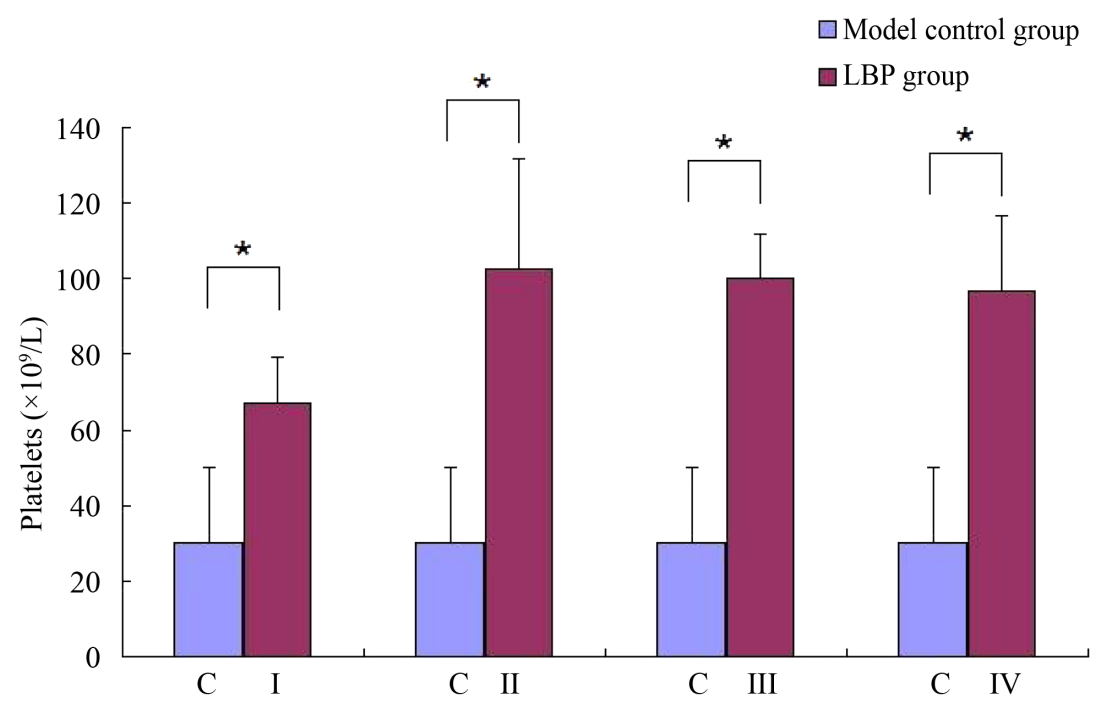

Figure 1. Platelet counts in peripheral blood of mice in each group. Expression (mean \pm SEM) of the platelet count was studied in the model control group and LBP group (including group I, group II, group III and group IV). * Significantly different between control group and LBP group $(P<0.05)$. 


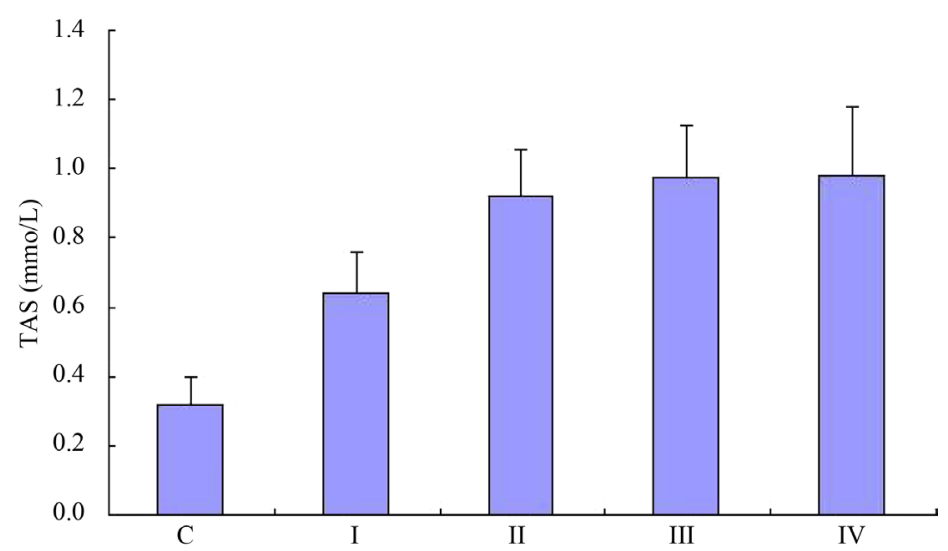

Figure 2. Serum total antioxidant status (TAS) was evaluated by enzyme-linked immunosorbent assay (ELISA) in each group. Expression (mean \pm SEM) of the concentration of TAS was studied in the model control group (C) or LBP groups (including group I, group II, group III and group IV). The concentration of TAS in all LBP groups was higher than that in the model control group after treatment for 7 days (all $P<0.01$ ).

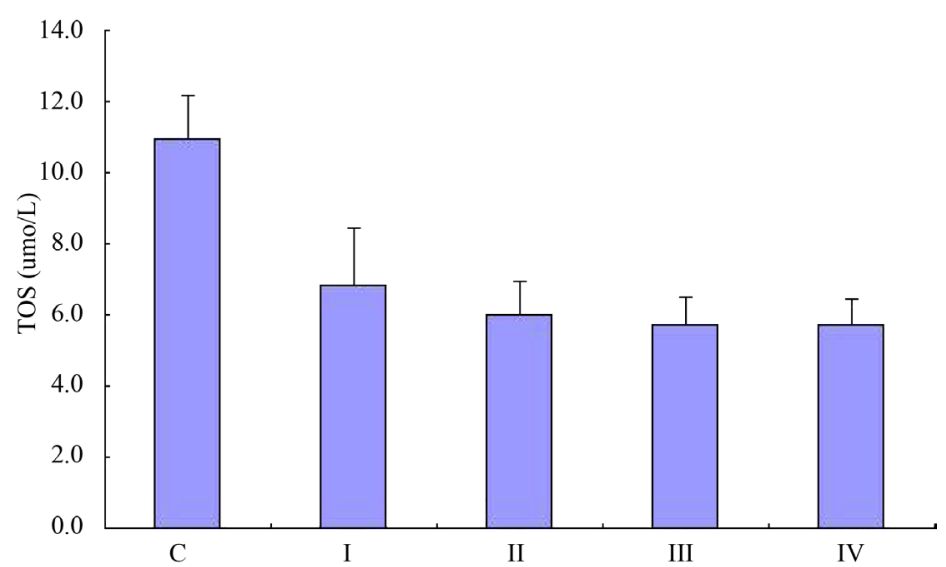

Figure 3. Serum total oxidant status (TOS) was evaluated by an enzyme-linked immunosorbent assay (ELISA) in each group. Expression (mean \pm SEM) of the concentration of TOS was studied in the model control group (C) or LBP group (including group I, group II, group III and group IV). The concentration of TOS in all LBP groups was lower than that in the model control group after treatment for 7 days (all $P<0.01$ ).

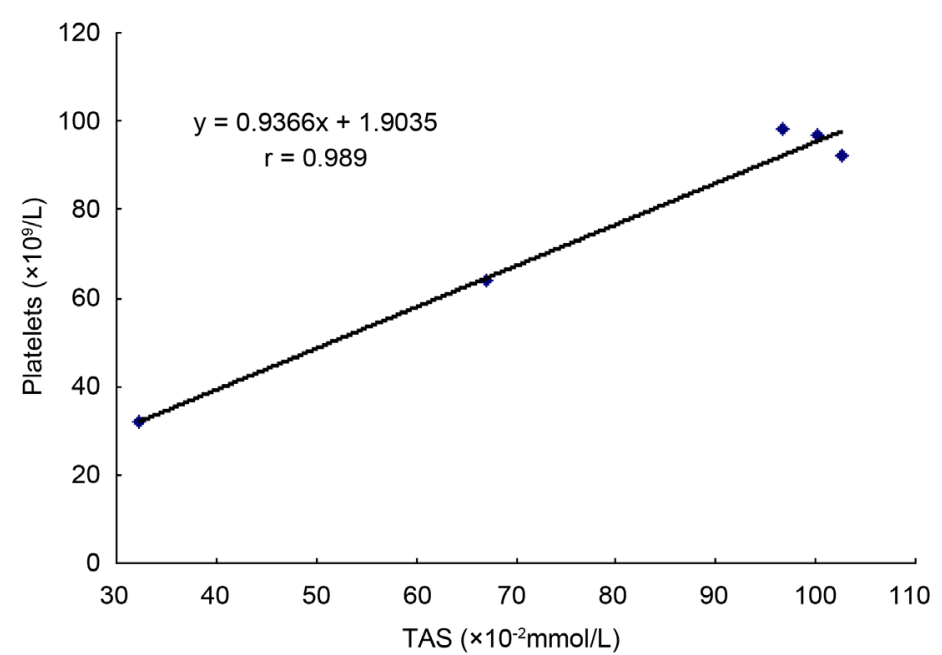

Figure 4. Correlation between platelet number and TAS. Platelet count showed a positive correlation with TOS $(r=0.989, P=$ 0.0005). 


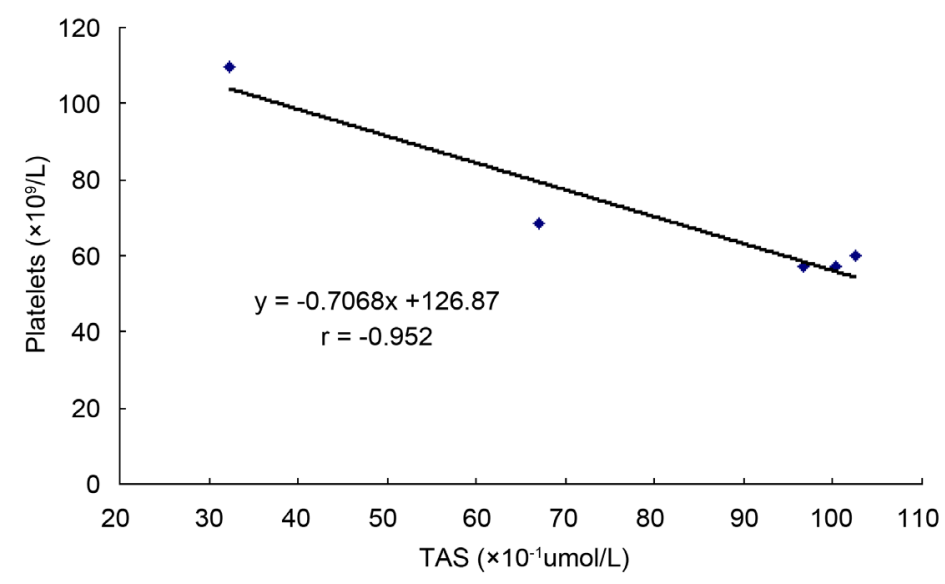

Figure 5. Correlation between platelet number and TOS. Platelet count showed a negative correlation with TOS $(r=-0.952, P=0.0009)$.

\section{Discussion}

Idiopathic thrombocytopenic purpura (ITP) is a bleeding disorder in which platelets are destroyed by the immune system. ITP is an autoimmune condition with antibodies detectable against several platelet surface antigens [6]. Corticosteroids, anti-D immunoglobulin, intravenous immunoglobulin, or immunosuppressive drugs were often used to cure the patients with very low counts or significant bleeding [7]. ITP occurs when certain immune system cells produce antibodies against platelets. The antibodies attach to the platelets. The spleen destroys the platelets that carry the antibodies [8] [9]; thus, ITP is sometimes called immune thrombocytopenic purpura. Persons with the disease have too few platelets in their blood [10]. Platelet count in humans and other mammals is very important for prevention of minor bleeding and for other immunological functions [11], but the exact molecular mechanism of ITP has not been fully known.

The polysaccharide in Ningxia wolfberry (Lycium bararum polysaccharides, LBP) is one of the important effective components. It consists of protein content which is very rare in vegetarian polysaccharides. LBP can regulate the differentiation and division of cells and control the growth of cells [12] [13]. Therefore, LBP has been used in healthy food processing and pharmacy manufacture widely.

LBP has many pharmacological functions and biological activities and is used to prevent and treat various chronic diseases, such as diabetes, male infertility, hypo-immune function, cancer, thrombosis, hepatitis and sexual behavior [14]-[18]. LBP was found to be comparable with the normal antioxidant vitamin C. Furthermore, adding vitamin $\mathrm{C}$ to the polysaccharide treatment further enhances the antioxidant activity of the polysaccharides in vivo [19]. We formerly reported that serum TAS, SOD, GSH, GSH-Px and CAT levels were significantly lower in patients with chronic ITP, while serum TOS, GSSG, NO, and MDA values were significantly higher. These findings indicated that oxidants increase in patients with chronic ITP, and these may be important factors in destroying the platelet membrane [3]. The research of free oxygen radicals provides a theoretical basis for treating ITP patients.

This study investigated the therapeutic effects of LBP treatment on ITP mice and its possible mechanism. We found that LBP significantly enhanced peripheral PLT recovery in ITP mice compared to the control group. The result indicated that LBP had a satisfactory therapeutic effect on ITP mice. TAS concentrations were significantly increased in the peripheral blood of mice administered with LBP, whereas TOS concentrations significantly decreased, indicating that LBP could treat ITP mice via suppressing oxidative stress. The reduction of oxidative stress may restore the immune system to normal in mice. Other specific mechanisms, such as if immune cells or immune molecules are involved in the healing of ITP, still need to be further explored.

\section{Acknowledgements}

All authors acknowledge the collaboration of Animal Center of Guangdong Medical College. This work was supported by the Nature Science Foundation of Shandong Province (Grant number: ZR2010HL038), Jining Municipal Science and Technology development projects (Grant number: 2012jnjc16 \& 2014jnnk23), Shandong provincial medical and health science and technology development project (Grant number: 2013WS033), Shan- 
dong Province Traditional Chinese medicine science and technology development project (Grant number: 2015244), and the Project of Shandong Province Higher Educational Science and Technology Program (Grant number: J15 LL11).

\section{References}

[1] Sanz, M.A., Vicente Garcia, V., Fernandez, A., Lopez, M.F., Grande, C., Jarque, I., et al. (2012) Guidelines for Diagnosis, Treatment and Monitoring of Primary Immune Thrombocytopenia. Medicina Clínica (Barc), 138, e1-e17. http://europepmc.org/abstract/med/22257609

[2] Xiao, J., Liong, E.C., Ching, Y.P., Chang, R.C., So, K.F., Fung, M.L., et al. (2012) Lycium barbarum Polysaccharides Protect Mice Liver from Carbon Tetrachloride-Induced Oxidative Stress and Necroinflammation. Journal of Ethnopharmacology, 139, 462-470. http://www.sciencedirect.com/science/article/pii/S0378874111008415 http://dx.doi.org/10.1016/j.jep.2011.11.033

[3] Jin, C.Q., Dong, H.X., Cheng, P.P., Zhou, J.W., Zheng, B.Y. and Liu, F. (2013) Antioxidant Status and Oxidative Stress in Patients with Chronic ITP. Scandinavian Journal of Immunology, 77, 482-487. http://dx.doi.org/10.1111/sji.12048

[4] Machino, Y., Ohta, H., Suzuki, E., Higurashi, S., Tezuka, T., Nagashima, H., et al. (2010) Effect of Immunoglobulin G (IgG) Interchain Disulfide Bond Cleavage on Efficacy of Intravenous Immunoglobulin for Immune Thrombocytopenic Purpura (ITP). Clinical \& Experimental Immunology, 162, 415-424. http://dx.doi.org/10.1111/j.1365-2249.2010.04255.x

[5] Teeling, J.L., Jansen-Hendriks, T., Kuijpers, T.W., de Haas, M., van de Winkel, J.G., Hack, C.E., et al. (2001) Therapeutic Efficacy of Intravenous Immunoglobulin Preparations Depends on the Immunoglobulin G Dimers: Studies in Experimental Immune Thrombocytopenia. Blood, 98, 1095-1099. http://www.bloodjournal.org/content/98/4/1095 http://dx.doi.org/10.1182/blood.v98.4.1095

[6] Gernsheimer, T. (2008) Epidemiology and Pathophysiology of Immune Thrombocytopenic Purpura. European Journal of Haematology, 80, 3-8. http://dx.doi.org/10.1111/j.1600-0609.2007.00998.x

[7] Thota, S., Kistangari, G., Daw, H. and Spiro, T. (2012) Immune Thrombocytopenia in Adults: An Update. Cleveland Clinic Journal of Medicine, 79, 641-650. http://europepmc.org/abstract/med/22949345 http://dx.doi.org/10.3949/ccjm.79a.11027

[8] Jin, C.Q., Liu, F., et al. (2011) The Changes and Clinical Significance of CD62P, PAIgG, Tr Cell in Children with Acute Idiopathic Thrombocytopenic Purpura Patients. International Journal of Pediatrics (China), 38, 96-99.

[9] Coopamah, M.D., Garvey, M.B., Freedman, J. and Semple, J.W. (2003) Cellular Immune Mechanisms in Autoimmune Thrombocytopenic Purpura: An Update. Transfusion Medicine Reviews, 17, 69-80. http://www.sciencedirect.com/science/article/pii/S0887796303800068 http://dx.doi.org/10.1053/tmrv.2003.50004

[10] Nakhoul, I.N., Kozuch, P. and Varma, M. (2006) Management of Adult Idiopathic Thrombocytopenic Purpura. Clinical Advances in Hematology and Oncology, 4, 136-144, 153. http://www.annualreviews.org/doi/abs/10.1146/annurev.med.56.082103.104644

[11] Schwartz, R.S. (2007) Immune Thrombocytopenic Purpura-From Agony to Agonist. New England Journal of Medicine, 357, 2299-2301.

http://www.antimicrobe.org/hisphoto/history/NEJM-Schwartz-Immune\%20thrombocytopenia-2007.pdf http://dx.doi.org/10.1056/NEJMe0707126

[12] Zhu, C.P. and Zhang, S.H. (2012) Lycium barbarum Polysaccharide Inhibits the Proliferation of HeLa Cells by Inducing Apoptosis. Journal of the Science of Food and Agriculture, 93, 149-156. http://dx.doi.org/10.1002/jsfa.5743

[13] Shen, L. and Du, G. (2012) Lycium barbarum Polysaccharide Stimulates Proliferation of MCF-7 Cells by the ERK Pathway. Life Sciences, 91, 353-357. http://www.sciencedirect.com/science/article/pii/S0024320512004250 http://dx.doi.org/10.1016/j.lfs.2012.08.012

[14] Cui, B., Chen, Y., Liu, S., Wang, J., Li, S., Wang, Q., et al. (2012) Antitumour Activity of Lycium chinensis Polysaccharides in Liver Cancer Rats. International Journal of Biological Macromolecules, 51, 314-318. http://www.sciencedirect.com/science/article/pii/S0141813012001651 http://dx.doi.org/10.1016/j.ijbiomac.2012.05.004

[15] Jin, M., Huang, Q., Zhao, K. and Shang, P. (2013) Biological Activities and Potential Health Benefit Effects of Polysaccharides Isolated from Lycium barbarum L. International Journal of Biological Macromolecules, 54, 16-23. http://www.sciencedirect.com/science/article/pii/S0141813012004655 http://dx.doi.org/10.1016/j.ijbiomac.2012.11.023

[16] Jing, L., Cui, G., Feng, Q. and Xiao, Y. (2009) Evaluation of Hypoglycemic Activity of the Polysaccharides Extracted 
from Lycium barbarum. African Journal of Traditional, Complementary and Alternative Medicines, 6, 579-584. http://www.ajol.info/index.php/ajtcam/article/view/57220

[17] Lau, B.W., Lee, J.C., Li, Y., Fung, S.M., Sang, Y.H., Shen, J., et al. (2012) Polysaccharides from Wolfberry Prevents Corticosterone-Induced Inhibition of Sexual Behavior and Increases Neurogenesis. PLoS One, 7, e33374. http://journals.plos.org/plosone/article?id=10.1371/journal.pone.0033374 http://dx.doi.org/10.1371/journal.pone.0033374

[18] Luo, Q., Li, Z., Huang, X., Yan, J., Zhang, S. and Cai, Y.Z. (2006) Lycium barbarum Polysaccharides: Protective Effects against Heat-Induced Damage of Rat Testes and $\mathrm{H}_{2} \mathrm{O}_{2}$-Induced DNA Damage in Mouse Testicular Cells and Beneficial Effect on Sexual Behavior and Reproductive Function of Hemicastrated Rats. Life Sciences, 79, 613-621. http://www.sciencedirect.com/science/article/pii/S0024320506001226 http://dx.doi.org/10.1016/j.lfs.2006.02.012

[19] Li, X.M., Ma, Y.L. and Liu, X.J. (2007) Effect of the Lycium barbarum Polysaccharides on Age-Related Oxidative Stress in Aged Mice. Journal of Ethnopharmacology, 111, 504-511. http://www.sciencedirect.com/science/article/pii/S0378874106006775 http://dx.doi.org/10.1016/j.jep.2006.12.024

\section{Submit or recommend next manuscript to SCIRP and we will provide best service for you:}

Accepting pre-submission inquiries through Email, Facebook, LinkedIn, Twitter, etc.

A wide selection of journals (inclusive of 9 subjects, more than 200 journals)

Providing 24-hour high-quality service

User-friendly online submission system

Fair and swift peer-review system

Efficient typesetting and proofreading procedure

Display of the result of downloads and visits, as well as the number of cited articles

Maximum dissemination of your research work

Submit your manuscript at: http://papersubmission.scirp.org/ 